Article

\title{
Temperature Effects on the Tensile Properties of Precipitation-Hardened Al-Mg-Cu-Si Alloys
}

\author{
J.B. Ferguson ${ }^{1}$, Hugo F. Lopez ${ }^{1}$, Kyu Cho ${ }^{2}$ and Chang-Soo Kim ${ }^{1}$ ** \\ 1 Materials Science and Engineering Department, University of Wisconsin-Milwaukee, Milwaukee, \\ WI 53211, USA; jbf2@uwm.edu (J.B.F.); hlopez@uwm.edu (H.F.L.) \\ 2 U.S. Army Research Laboratory, Weapons and Materials Research Directorate, Aberdeen Proving Ground, \\ MD 21005, USA; kyu.c.cho2.civ@mail.mil \\ * Correspondence: kimcs@uwm.edu; Tel.: +1-414-229-3085
}

Academic Editor: Nong Gao

Received: 5 January 2016; Accepted: 15 February 2016; Published: 23 February 2016

\begin{abstract}
Because the mechanical performance of precipitation-hardened alloys can be significantly altered with temperature changes, understanding and predicting the effects of temperatures on various mechanical properties for these alloys are important. In the present work, an analytical model has been developed to predict the elastic modulus, the yield stress, the failure stress, and the failure strain taking into consideration the effect of temperatures for precipitation-hardenable Al-Mg-Cu-Si Alloys (Al-A319 alloys). In addition, other important mechanical properties of Al-A319 alloys including the strain hardening exponent, the strength coefficient, and the ductility parameter can be estimated using the current model. It is demonstrated that the prediction results based on the proposed model are in good agreement with those obtained experimentally in Al-A319 alloys in the as-cast condition and after $\mathrm{W}$ and $\mathrm{T} 7$ heat treatments.
\end{abstract}

Keywords: precipitation-hardened alloys; $\mathrm{Al}$ alloys; tensile properties; temperature effects; property modeling

\section{Introduction}

Precipitation-hardened alloys or age-hardened alloys based on $\mathrm{Al}, \mathrm{Mg}, \mathrm{Ni}$, and/or Ti are widely used in structural applications due to the enhanced strength that can be achieved by heat treating [1-3]. The mechanical properties of these types of alloys are deeply influenced by (i) the thermodynamic stability of the precipitates in the alloys; and (ii) the concentration of impurity elements that influence which precipitates ultimately evolve in the alloy microstructure. Because differing heat treatment procedures are employed to control the quantity, size, and composition of the intermetallics that form in the alloys, it is possible to develop different combinations of room temperature strength and ductility. However, these alloys are frequently used in applications well above room temperature, where the effect of heat treatment/precipitation condition is not well-described in general. Al alloy A319 (Al-A319) is a good example of this type of alloy. Al-A319 cast alloys have been increasingly used in the manufacture of engine blocks due to a combination of good abrasive properties and mechanical strength [1-3]. The microstructural constituents present in this alloy are typically complex multiphases comprising eutectic (acicular) $\mathrm{Si}$ as well as numerous intermetallic phases. Al-A319 alloys nominally contain several percents of $\mathrm{Si}$. Other elements such as $\mathrm{Cu}$ and $\mathrm{Mg}$ are typically incorporated in Al-A319 alloys to improve the room and high temperature strength [4,5].

Because yield strength, failure stress, strain-to-failure, and strain hardening coefficient that can be varied depending on different service temperatures are key factors to determine the performance of precipitation-hardened alloys, it would be advantageous to have a prediction model to describe 
the temperature-dependent behavior of these types of alloys. However, despite the long history of developing these precipitation-hardened alloys in the metallurgy field, there are no tools to estimate the temperature dependence of the mechanical properties of the alloys. In the present study, therefore, an analytical model involving an empirical fitting approach has been developed to predict the dependence of temperature on strength, ductility, and strain hardening coefficient of precipitation-hardened alloys. We previously developed an analytical model to predict the tensile and compressive properties of bimodal metallic materials at room temperature [6]. The model showed how the properties of true yield stress, true failure stress, strain hardening exponent, strain-to-failure, and a newly defined ductility parameter are interrelated. The interrelatedness of these parameters need not be limited to only bimodal materials. In this work, an extended version of the model is proposed to account for the effect of temperature on Young's modulus, true yield stress, true failure stress, and strain-to-failure for precipitation-hardened alloys. We will show that, from these basic parameters, all other mechanical parameters of interest including strength coefficient, ductility parameter (which will be described later), and strain hardening exponent can be calculated. The prediction results of these combined models were compared to experimental data from tensile tests of Al-A319 alloys in the as-cast, W (solutionized for $4.5 \mathrm{~h}$ at $450{ }^{\circ} \mathrm{C}$ ), and $\mathrm{T} 7\left(\mathrm{~W}\right.$ treatment + age-hardened for $4.67 \mathrm{~h}$ at $230{ }^{\circ} \mathrm{C}$ ) heat treatment conditions. Specimens with $\mathrm{W}$ and $\mathrm{T} 7$ heat treatment conditions were selected in this work because solutionization (i.e., $\mathrm{W}$ condition) and subsequent age-hardening (i.e., $\mathrm{T} 7$ condition) are commonly applied to Al-A319 alloys to reduce the residual stress accumulated during the casting process and to improve homogeneity in the microstructure of materials. Because of the relatively short time intervals between the $\mathrm{W}$ heat treatment and the tensile testing, the effect of natural aging was not considered in the current work.

\section{Analytical Model Development}

\subsection{Temperature-Dependent Model}

Based on the evaluation of experimental data, the empirical relationships of Equations (1) to (5) are proposed to account for the temperature-dependent properties of Young's modulus $(Y)$, true yield stress $\left(\sigma_{t-y}\right)$, true failure stress $\left(\sigma_{t-\text { fail }}\right)$, and strain-to-failure $\left(\varepsilon_{t-\text { fail }}\right)$.

Previous research has shown that the Young's modulus of pure Al decreases linearly with temperature from some initial maximum value, $Y_{0}$ [7]. However, in alloy systems, the behavior is more complicated and often shows a more marked non-linear decrease. We assume that the behavior of the Young's modulus can be adequately described by a transitional function such as the logistic function to account for such non-linearity. This is based on an assumption that the Young's modulus of $\mathrm{Al}$ alloys would not be much influenced by the temperature changes at extreme temperatures, which is true near the melting temperature and at very low temperature. The logistic function requires the use of a low temperature Young's modulus value, $Y_{\mathrm{LT}}$, as well as a high temperature value, $Y_{\mathrm{HT}}$. The subscripts LT and HT denote low temperature and high temperature, respectively. It would be reasonable to consider these LT and HT are the temperatures that are applicable as the lower and upper bound of the logistic function. Therefore, we set the initial maximum value of modulus, $Y_{0}$, as the $Y_{\text {LT }}$. Based on this, in this work, Equation (1) is used to describe the Young's modulus $(Y)$ as a function of temperature $(T)$ using suitable choices of empirical constants.

$$
Y=Y_{0}-\frac{\Delta Y}{\Delta T} T-\frac{Y_{L T}-Y_{H T}}{1+e^{\left(T^{*}-T\right) / \Psi}}=Y_{L T}-\frac{\Delta Y}{\Delta T} T-\frac{Y_{L T}-Y_{H T}}{1+e^{\left(T^{*}-T\right) / \Psi}}
$$

In Equation (1), $T^{*}$ is the alloy softening temperature at which Young's modulus with temperature shows the highest rate of change (i.e., the highest $\frac{\mathrm{d} Y}{\mathrm{~d} T}$ ) [8]. Here, $\Psi$ represents another experimentally determined transition parameter to govern the rapidity with which the transition takes place. As will be demonstrated in the "Results and Discussion" section, the linear dependence term $\left(\frac{\Delta Y}{\Delta T} T\right)$ in 
Equation (1) does not considerably affect the variations of the Young's modulus with temperature changes for the Al-A319 systems considered in this work.

The temperature dependence of true yield stress $\left(\sigma_{t-y}\right)$ is determined by adjusting the low temperature true yield stress $\left(\sigma_{t-y_{L T}}\right)$ for the loss of stiffness that accompanies the increase in temperature. We approximate that this adjustment would be proportional to the elastic portion of the true yield strain, i.e., $\varepsilon_{t-y_{L T}}=\sigma_{t-y_{L T}} / Y_{L T}$, and the elastic modulus difference, i.e., $\left(Y_{L Y}-Y\right)$, as given in Equation (2), where $C_{y}$ is an empirically determined proportionality constant. This implies that the decrease in the $\sigma_{t-y_{L T}}$ could be linearly approximated by the change in the Young modulus with temperature, $\left(Y_{L Y}-Y\right)$. Here, note that we do not claim that the loss of true yield strength is the same as the product of the elastic portion of the true yield strain and the elastic modulus difference. Instead, we attempted to describe the true yield stress behaviors using the simplest approach.

$$
\sigma_{t-y}=\sigma_{t-y_{L T}}-C_{y}\left(\frac{\sigma_{t-y_{L T}}}{Y_{L T}}\right)\left(Y_{L T}-Y\right)=\sigma_{t-y_{L T}}\left[1-C_{y}\left(\frac{Y_{L T}-Y}{Y_{L T}}\right)\right]
$$

Now, the temperature dependence of the true failure stress $\left(\sigma_{t-\text { fail }}\right)$ can be determined in the same manner, where the adjustment is likewise proportional to the elastic portion of the true failure strain, $\varepsilon_{t-\text { fail }_{L T}}=\sigma_{t-f a i l_{L T}} / Y_{L T}$, and the elastic modulus difference, $\left(Y_{L Y}-Y\right)$.

$$
\sigma_{t-\text { fail }_{1}}=\sigma_{t-\text { fail }_{L T}}-C_{\text {fail }}\left(\frac{\sigma_{t-\text { fail }_{L T}}}{Y_{L T}}\right)\left(Y_{L T}-Y\right)=\sigma_{t-\text { fail }_{L T}}\left[1-C_{\text {fail }}\left(\frac{\Upsilon_{L T}-Y}{Y_{L T}}\right)\right]
$$

In Equation (3), $C_{\text {fail }}$ is a proportionality constant that can be empirically determined. Note that $C_{y}$ and $C_{\text {fail }}$ values would be varied by the material systems of interest. In the case of Al-A319 for all heat treatment conditions, it was found that $C_{y}=C_{\text {fail }}$, which indicates that the decreasing rates of $\sigma_{t-y}$ and $\sigma_{t-\text { fail }}$ are same from their LT values $\left(C_{y}=C_{\text {fail }}\right)$.

For the representation of the true failure strain $\left(\varepsilon_{t-\text { fail }}\right)$, it is proposed that $\varepsilon_{t-\text { fail }}$ can be described by the Arrhenius-like Equation (4) in which true failure strain $\left(\varepsilon_{t-\text { fail }}\right)$ increases as temperature increases up to the solidus temperature of the metal ( $\left.T_{\text {solidus }}\right)$.

$$
\begin{gathered}
\ln \frac{\varepsilon_{t-\text { fail }}}{\varepsilon_{t-\text { fail }}^{*}}=\frac{-Q_{\text {fail }}}{R\left(T-T_{\text {solidus }}\right)} \\
\varepsilon_{t-\text { fail }}=\varepsilon_{t-\text { fail }}^{*} \exp \left(\frac{-Q_{\text {fail }}}{R\left(T-T_{\text {solidus }}\right)}\right)
\end{gathered}
$$

where $Q_{\text {fail }}$ is the activation energy change for failure and $R$ is the gas constant, respectively. In Equations (4) and (5), mathematically, $\varepsilon_{t-f a i l}^{*}$ corresponds to the failure strain of alloys at infinitely low temperature (i.e., $T \approx-\infty$ ). Physically, it would be reasonable to approximate as $\varepsilon_{t-f a i l}^{*}=Y_{L T} / \sigma_{t-\text { fail }}$ at LY. The parameter $Q_{\text {fail }}$ can be determined using linear regression analysis. Here, $\ln \varepsilon_{t-f a i l}^{*}$ and $Q_{\text {fail }}$ can be graphically interpreted as the y-intercept value and the slope of $\ln \varepsilon_{t-\text { fail }} v s . \frac{-1}{R\left(T-T_{\text {solidus }}\right)}$ plot, respectively.

\subsection{Interrelated Mechanical Properties}

There are advanced models to describe the evolution of dislocation densities upon processing and the subsequent hardening behavior of alloys. These models include the Kocks-Mecking model [9-11], the Alflow model [12], and Myhr et al.'s model [13]. Although these sophisticated models may include the effects of stacking fault energy, grain size, impurity element content, precipitation particle sizes/contents, etc., on the hardening behavior of alloys, we elected to use a simpler Hollomon equation $\left(\sigma_{t}=K \varepsilon_{t}{ }^{n}\right.$, where $\sigma_{t}, \varepsilon_{t}, K$, and $n$ are true stress, true strain, strength coefficient, and strain hardening exponent, respectively) to represent the hardening behavior of Al-A319 alloys. When the 
work hardening phenomena of the material can be described by the Hollomon relationship, then Equations (6) and (7) can be used to determine $n$ and $K$ [6].

$$
\begin{gathered}
n=\frac{\ln \left(\sigma_{t-f a i l} / \sigma_{t-y}\right)}{\ln \left(\varepsilon_{t-f a i l} / \varepsilon_{t-y}\right)} \\
K=\frac{\sigma_{t-y}}{\varepsilon_{t-y}^{n}}
\end{gathered}
$$

The ductility parameter $(A)$ is defined as the area under the $\left(\ln \sigma_{t} v s\right.$. $\left.\ln \varepsilon_{t}\right)$ curve between the yield stress and maximum (i.e., failure) stress [6]. This parameter is considered to govern the ductility of the material and is defined by Equation (8).

$$
A=\frac{\ln \left(\sigma_{t-y} \sigma_{t-f a i l}\right)}{2} \ln \left(\varepsilon_{t-f a i l} / \varepsilon_{t-y}\right)
$$

\section{Experimental Section}

To compare the results based on the analytical models developed in the previous section, Al-A319 alloy was supplied in the form of sectioned chilled blocks of $100 \mathrm{~mm} \times 15 \mathrm{~mm} \times 15 \mathrm{~mm}$ having a dendrite arm spacing (DAS) ranging from 20 to $50 \mu \mathrm{m}$. In this alloy, Si modification and grain refinement were achieved by employing an Al- $10 \%$ Sr master alloy, and a commercial Ti-B (5\% Ti-1\% B) alloy. Final composition of the alloy was Al-8.6 Si-3.8 Cu-0.36 Mg-0.5 Fe-0.3 Mn-0.012 Sr-0.05 Cr-0.023 Ni-0.015 Pb. From the chilled as-cast blocks, square bars were cut and heat-treated resulting in the following material conditions: (a) as-cast, (b) $\mathrm{W}$-solutionized $\left(4.5 \mathrm{~h}\right.$ at $450{ }^{\circ} \mathrm{C}$ ) and (c) T7-age-hardened ( $\mathrm{W}$ treatment $+4.67 \mathrm{~h}$ at $230^{\circ} \mathrm{C}$ ). Figure 1 shows the micrographs for (a) as-cast and (b) W specimens obtained using optical microscope (Olympus model Mx50, Olympus Corp., Center Valley, PA, USA). In the micrographs, light and dark contrasts generally represent the $\alpha$-Al and modified Si particles in Al-A319 alloys, respectively. As can be seen in Figure 1, after W heat treatments, the general microstructures did not exhibit much difference from the microstructure of original as-cast specimen. Micrographs from T7 conditions also displayed similar microstructures to those from the as-cast and $\mathrm{W}$ conditions.
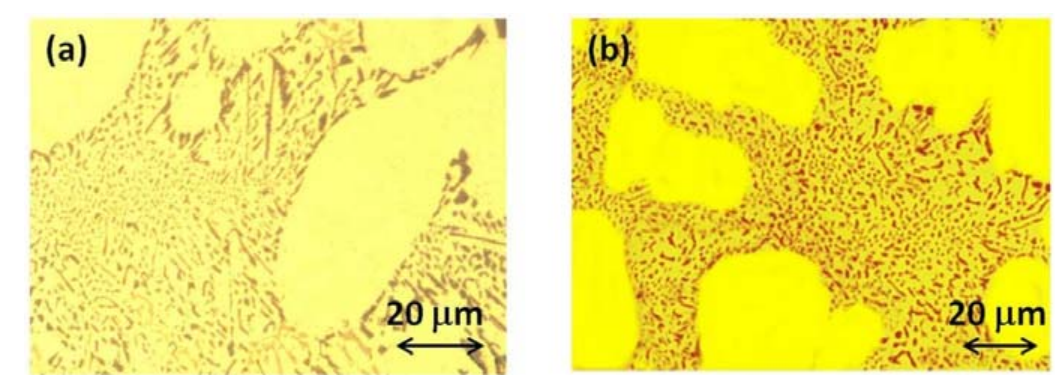

Figure 1. Optical micrographs from the (a) as-cast; and (b) W specimens. Light and dark contrasts generally represent the $\alpha$-Al phase and the modified Si particles in the Al-A319 alloys, respectively.

Tensile specimens of the as-cast and heat treated bars were then machined into samples $9 \mathrm{~mm}$ in diameter and $80 \mathrm{~mm}$ in length according to the ASTM standards E21-921998 and B557-02. Tensile testing was carried out on an MTS 810 machine (MTS Systems Corp., Eden Prairie, MN, USA) at a strain rate of $10^{-4} \mathrm{~s}^{-1}$. The tensile testing machine was instrumented with an ambient chamber to maintain the testing temperatures within $\pm 2{ }^{\circ} \mathrm{C}$. Tensile testing was carried out at $-90,-60,-30$, $0,150,180,210,240,270,320,370$, and $400{ }^{\circ} \mathrm{C}$. Prior to tensile testing, the specimens were heated to the desired temperature and held for approximately $10 \mathrm{~min}$ to achieve temperature stability. Up to four samples were tested at each test temperature to obtain statistically reliable tensile testing 
results. An extensometer (axial extensometer Epsilon 3542, Epsilon Technology Corp., Jackson, WY, USA) was placed on the gage length and total elongation values were measured to the points of fracture. Figure 2 shows the examples of stress-strain curves at $-90,0,150,270$, and $400{ }^{\circ} \mathrm{C}$ measured using these (a) as-cast, (b) W, and (c) T7 specimens, respectively. Experimental Young's modulus ( $Y$ ), true yield stress $\left(\sigma_{t-y}\right)$, true failure stress $\left(\sigma_{t-\text { fail }}\right)$, true failure strain $\left(\varepsilon_{t}\right.$-fail $)$, strength coefficient $(K)$, ductility parameter $(A)$, and strain hardening exponent $(n)$ data were extracted based on these tensile testing results.
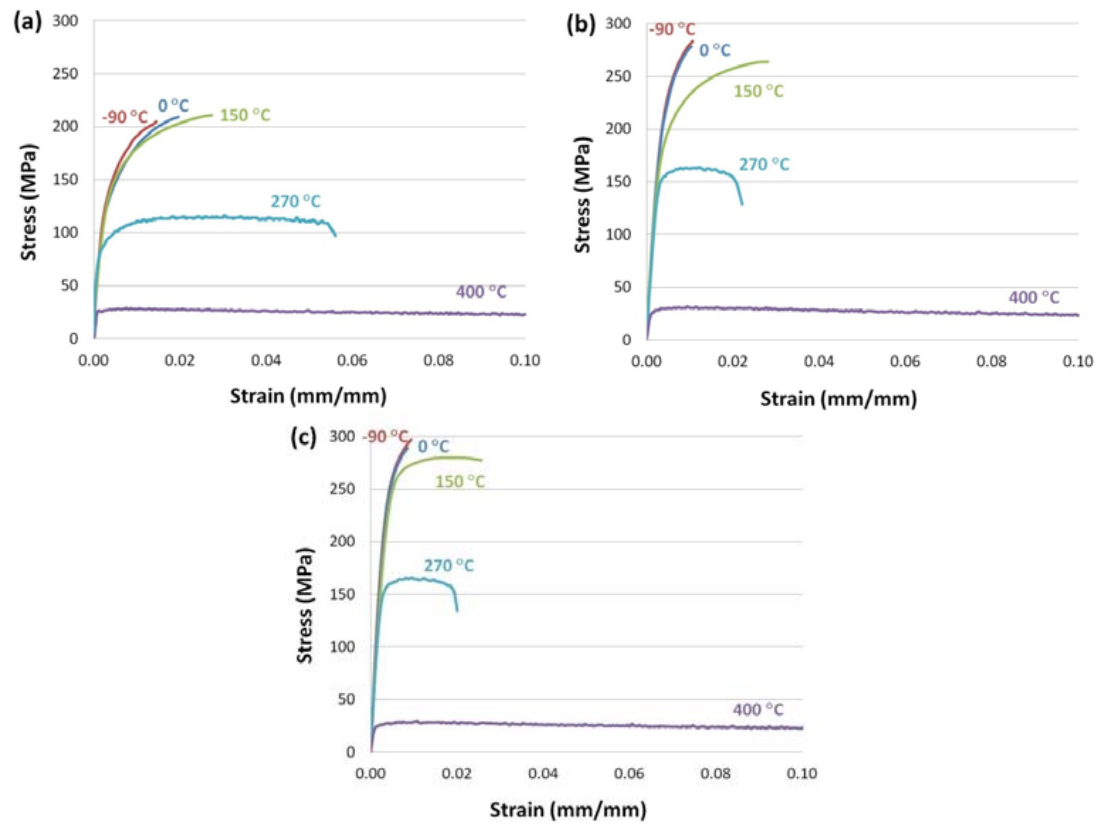

Figure 2. Examples of tensile stress-strain curves at various temperatures $\left(-90,0,150,270\right.$, and $\left.400{ }^{\circ} \mathrm{C}\right)$ from (a) as-cast; (b) W; and (c) T7 specimens.

\section{Results and Discussion}

Using the property prediction model developed above and the experimentally/empirically determined values of parameters contained in Table 1, Figures 3-7 present the predicted property values in comparison to the results obtained from the tensile tests of Al-A319 alloys. In Table 1, the parameters $\left(\Psi, C_{y}, C_{\text {fail }}\right.$, and $\left.Q_{\text {fail }}\right)$ in the shaded boxes were empirically-determined and all other parameters were experimentally determined.

Table 1. Experimental and empirical model parameters for Al-A319 alloys in various heat treatment conditions.

\begin{tabular}{|c|c|c|c|c|}
\hline Property & Parameters & As-Cast & $\mathbf{W}$ & T7 \\
\hline \multirow{5}{*}{$Y(\mathrm{MPa})$} & $\Delta Y / \Delta T\left(\mathrm{MPa} \cdot \mathrm{K}^{-1}\right)$ & & 0 & \\
\hline & $Y_{0}=Y_{\mathrm{LT}}(\mathrm{MPa})$ & & 74,000 & \\
\hline & $Y_{\mathrm{HT}}(\mathrm{MPa})$ & & 30,000 & \\
\hline & $T^{*}\left({ }^{\circ} \mathrm{C}\right)$ & & 300 & \\
\hline & $\Psi\left({ }^{\circ} \mathrm{C}\right)$ & & 55 & \\
\hline \multirow{2}{*}{$\sigma_{t-y}(\mathrm{MPa})$} & $\sigma_{t-y_{L T}}(\mathrm{MPa})$ & 141.0 & 240.0 & 262.0 \\
\hline & $C_{y}$ & & 1.6 & \\
\hline \multirow{2}{*}{$\sigma_{t-\text { fail }}(\mathrm{MPa})$} & $\sigma_{t-f_{t a i}}(\mathrm{MPa})$ & 211.0 & 279.0 & 292.0 \\
\hline & $C_{\text {fail }}$ & & 1.6 & \\
\hline \multirow{3}{*}{$\varepsilon_{t-\text { fail }}(\%)$} & $\varepsilon_{t-\text { fail }}^{*}(\%)$ & 0.2851 & 0.3770 & 0.3946 \\
\hline & $Q_{\text {fail }}\left(\mathrm{J} \cdot \mathrm{mol}^{-1}\right)$ & 5269.6 & 3906.4 & 3932.1 \\
\hline & $T_{\text {solidus }}\left({ }^{\circ} \mathrm{C}\right)$ & & 515 & \\
\hline
\end{tabular}


It is important to note that the Al-A319 chemical composition is such that many different types of intermetallics are evolved during solidification, some of which can be dissolved by a solutionizing heat treatment and others (especially Fe-containing species) that cannot $[8,14]$. Rincon et al. $[8,14]$ have shown that these brittle intermetallics can be large and significantly degrade tensile properties due to their tendency to initiate and propagate cracks. In Al-A319 in particular, and precipitation-hardenable alloys in general, the as-cast condition is likely to have a variety of intermetallics that are non-uniformly distributed throughout the material. This is due to differences in cooling rates in various parts of the casting, which causes differing degrees of concentration gradients during the solidification. Differences in cooling rate will also result in variability in grain size and grain morphology. Both of these factors will affect the mechanical properties. Therefore, it is to be expected that the material properties of the as-cast metal will possess the most variability. Material in the $\mathrm{W}$ condition would be expected to show less variability due to the homogenizing effect of the solutionizing treatment, where some intermetallics are dissolved, and differences in grain sizes are to a certain extent evened out. The material in the T7 condition would be expected to show the least variability in mechanical properties, because (i) it has undergone the solutionizing heat treatment to form more homogenous microstructure; and (ii) it derives its strength primarily from the Orowan strengthening mechanism [15], which depends on concentration, size, and distribution of nanoscopic precipitates-making it relatively insensitive to grain size effects on the yield stress of alloys.

Figure 3 shows the temperature-dependence of Young's modulus for Al-A319 alloys in various heat treatment conditions. In the figure, the symbols and dashed curve represent experimental data and the prediction of the model using Equation (1), respectively. It should be noted that in the case of the Young's modulus of Al-A319, the scatter in the data does not allow for the adequate determination of the slight linear decrease in Young's modulus $(\Delta Y / \Delta T=0)$. Therefore, to include a more marked non-linearity in Equation (1), $\Delta Y / \Delta T$ was set to 0 for all heat treatment conditions. Also, because the modulus did not decrease with decreasing temperature below room temperatures, we selected $Y_{0}\left(=Y_{\mathrm{LT}}\right)$ as the nominal modulus of Al-319, i.e., $74 \mathrm{GPa}$. The Young's modulus at HT was assumed as the $Y_{\mathrm{HT}}$ at $T_{\text {solidus }}$ and was asymptotically extrapolated based on the experimental measurement data (i.e., $Y_{\mathrm{HT}} \approx 30 \mathrm{GPa}$ ). The alloy softening temperature $\left(T^{*}\right)$ was set as $300{ }^{\circ} \mathrm{C}$ for all of the Al-A319 alloy systems tested in the present study [8]. The transition parameter $(\Psi)$ of the logistic function is the only empirical parameter to describe the temperature-dependent behaviors of the Young's modulus. As shown in Figure 3, the experimental measurements exhibit considerable scatter in the Young's modulus. In particular, the Young's moduli of the as-cast sample show large variations, and the measured values sometimes display a decreasing trend with decreasing temperatures, which can be explained by the inhomogeneous non-uniform distributions of intermetallics as addressed in the previous paragraph. Though there is considerable scatter in the modulus data, Figure 3 shows that Equation (1) with the empirically determined transition parameter ( $\Psi$ ) value of $55{ }^{\circ} \mathrm{C}$ provides an adequate description of the temperature-dependent behavior of the material. Due to the scatter, it was not feasible to determine if Young's modulus depends significantly on the heat treatment conditions. A significant difference in the modulus would only be expected if (i) the various intermetallic or dispersed phases in the different heat treated materials are substantially more or less stiff than the metallic phase; and (ii) the intermetallics are present in sufficient concentrations that they have a non-negligible effect. Examination of microstructures with different heat treatment conditions did not show such difference. Further, from Figure 3, it is clear that any obvious trend is not observed among the as-cast, W, and, T7 samples. In addition, because the Young's modulus used in Equations (2) and (3) to predict the yield $\left(\sigma_{t-y}\right)$ and failures stresses $\left(\sigma_{t-\text { fail }}\right)$ will demonstrate below that these predictions are seemingly accurate, the assumption that Young's modulus is roughly independent of the heat treatment conditions seems justified as a first approximation, at least in the case of Al-A319 alloys considered in the present work. 


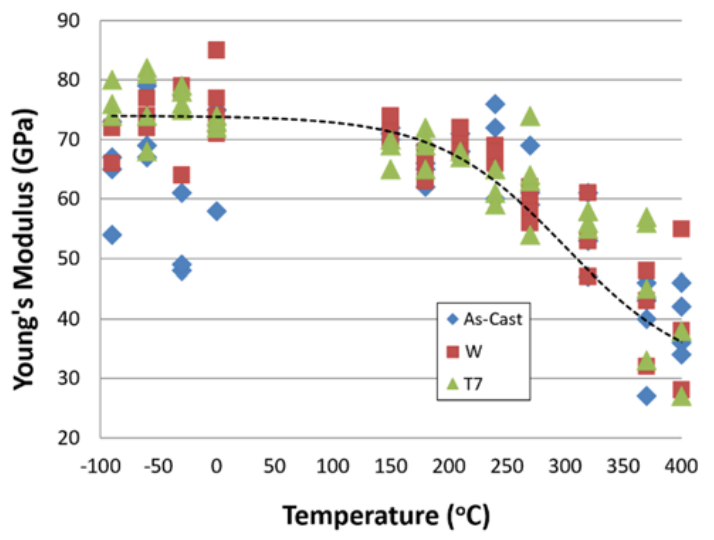

Figure 3. Temperature-dependence of Young's modulus for Al-A319 in various heat treatment conditions. Symbols represent experimental data and the dashed curve is the prediction of the model, respectively.

In Figure 4, using Equations (2) and (3), the temperature dependence of (a) true yield stress $\left(\sigma_{t-y}\right)$ and $(\mathrm{b})$ true failure stress $\left(\sigma_{t-\text { fail }}\right)$ for Al-A319 alloys in various heat treatment conditions is plotted. Again, symbols represent experimental data and the curves are the prediction of the model, respectively. The $\sigma_{t-y_{L T}}$ and $\sigma_{t-f a i l_{L T}}$ values were determined by the averages of $\sigma_{t-y}$ and $\sigma_{t-\text { fail }}$ in the temperature ranges of $-90^{\circ} \mathrm{C}$ and $30^{\circ} \mathrm{C}$, because it was observed that these properties are not affected by the temperature below the room temperature for Al-A319 alloys [8]. In determining the experimental $\sigma_{t-y}$ values, we used the $0.2 \%$ offset method from the measured stress-strain curves. By the regression analysis, we identified that the proportionality constant $C_{y}$ and $C_{\text {fail }}$ values of 1.6 produce the best-fit to the experimental observations. This implies that the loss of $\sigma_{t-y}$ and $\sigma_{t-\text { fail }}$ from LT due to the temperature increase can be successfully expressed by the multiples of elastic true strain of LT and the loss conversion constants for both cases are 1.6. Also, this validates that the approximation of Equations (2) and (3) could be applied to the estimation of true yield stress and true failure strain in Al-A319 systems considered in this work. From the figure, it is seen that the analytical prediction shows good agreements with the experimental observations. As expected, Figure 4a clearly shows that true yield stress $\left(\sigma_{t-y}\right)$ depends significantly on the heat treatment conditions. Figure $4 \mathrm{~b}$ indicates that in general the as-cast material fails at much lower stresses compared with the W and T7 materials. Low failure stress is likely the result of higher concentrations of brittle intermetallics in grain boundary regions of the as-cast material. It is, however, notable that, at a given temperature, there is little difference between the failure stresses $\left(\sigma_{t-\text { fail }}\right)$ of the $\mathrm{W}$ and $\mathrm{T} 7$ conditions, though age-hardening (i.e., T7) induces slightly higher yield stress $\left(\sigma_{t-y}\right)$. It is known from Al-5083 bimodal materials that the grain size has a significant effect on the failure stress [6], but it would appear that in homogenized Al-A319 (i.e., $\mathrm{W}$ and $\mathrm{T} 7$ samples), the failure stress is influenced by alloy composition (i.e., chemical composition) rather than the concentration, size, and distribution of precipitates. This indicates it is likely that grain size and chemical composition primarily control failure stress in homogenized Al-A319. An analysis of failure stress data from Talamantes-Silva et al. [16] for Al-206 in W and T7 heat treat conditions over a range of grain sizes has shown that there is also little difference in true failure stress between $\mathrm{W}$ and T7 conditions if the samples have the same grain size. It is, however, thought that further investigation would be necessary to determine if this is the case for alloys other than Al-A319 and Al-206. At temperatures of $210{ }^{\circ} \mathrm{C}$ and $270{ }^{\circ} \mathrm{C}$, the behavior of the as-cast material significantly departs from its general behavior and takes on the attributes of the $\mathrm{T} 7$ material. However, at a temperature of $240^{\circ} \mathrm{C}$, the behavior exhibits its predicted behavior. The $\mathrm{W}$ material also seems to take on the attributes of the $\mathrm{T} 7$ material in the temperature range of $210^{\circ} \mathrm{C}$ to $240^{\circ} \mathrm{C}$. The abrupt changes in behavior are likely due to the dissolution and/or precipitation of various intermetallic phases. At temperatures of $300{ }^{\circ} \mathrm{C}$ (i.e., alloy softening temperature) and above, there appears to be little difference between the materials. 

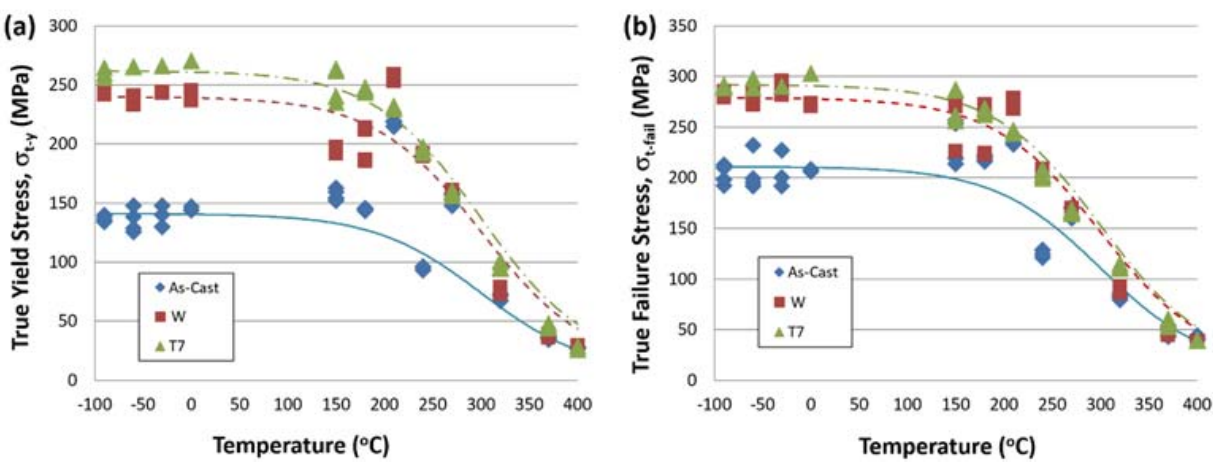

Figure 4. Temperature-dependence of (a) true yield stress $\left(\sigma_{t-y}\right)$; and (b) true failure stress $\left(\sigma_{t-\text { fail }}\right)$ for Al-A319 alloys in various heat treatment conditions. Symbols represent experimental data and the curves are the prediction of the model, respectively.

Figure 5 shows the Arrhenius-like dependence of true failure strain $\left(\varepsilon_{t-\text { fail }}\right)$ for Al-A319 alloys using the expression given in Equations (4) and (5) in (a) as-cast, (b) W, and (c) T7 heat treatment conditions. Again, the symbols represent experimental data and the lines are the prediction of the model, respectively. $\varepsilon_{t-f a i l}^{*}$ values were calculated using $\varepsilon_{t-f a i l}^{*}=Y_{L T} / \sigma_{t-\text { fail }}$ for each heat treatment condition. After obtaining the $y$-intercept values $\left(\varepsilon_{t-f a i l}^{*}\right)$, the linear regression was used to predict the slopes shown in Figure 5. $R$-squared values $\left(R^{2}\right)$ of the linear regression are also provided in the figure. The data in the figure evidently exhibit a higher true failure strain $\left(\varepsilon_{t-\text { fail }}\right)$ with higher temperature (i.e., higher $\left.\frac{-1}{R\left(T-T_{\text {solidus }}\right)}\right)$. From the figures, it is clearly seen that the predictions from the proposed Equation (4) provide a reasonably accurate estimate of the true failure strain $\left(\varepsilon_{t-\text { fail }}\right)$, although there are instances in the as-cast and $\mathrm{W}$ data where there is some departure from the general trend. The slopes of the prediction lines in Figure 5 can be used to understand the temperature effects on the changes of the true failure strain $\left(\varepsilon_{t-\text { fail }}\right)$. From the figure, it is seen that the true failure strain $\left(\varepsilon_{t-\text { fail }}\right)$ of the as-cast sample shows the highest failure activation energy (i.e., high $Q_{\text {fail }}$ value in Equations (4) and (5)), while the heat treated samples (W and T7) show a lower failure activation energy (i.e., smaller $Q_{\text {fail }}$ value in Equations (4) and (5)). This can be explained from the different microstructural homogeneity of as-cast and heat treatment samples. As-cast materials possess a large variation in intermetallic phase size, shape, and composition, and therefore, possess many inhomogeneous microstructural features that could lead to failure. Hence, the as-cast samples likely show more temperature-sensitive behavior for the strain failure. On the other hand, $\mathrm{W}$ and $\mathrm{T} 7$ materials are more refined and homogenous and thus the types/degrees of defects that can cause failure are less in these solutionized and age-hardened materials, which will exhibit less sensitivity to the temperature changes with regards to the temperature changes.
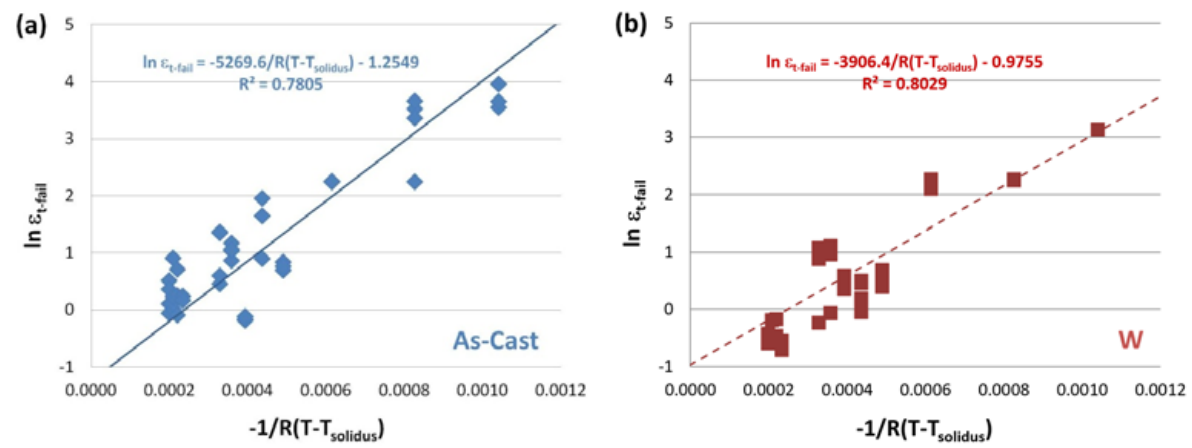

Figure 5. Cont. 


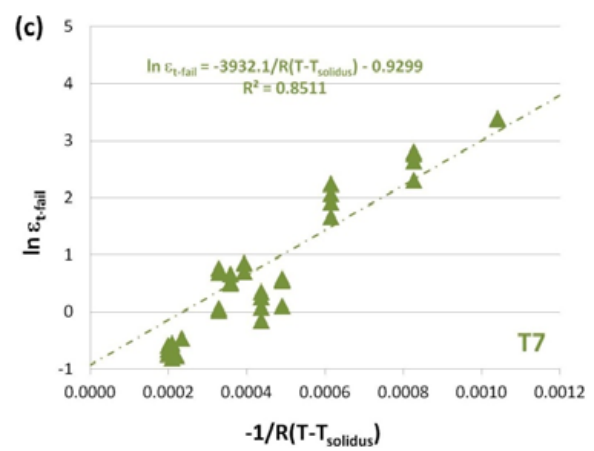

Figure 5. Arrhenius-like dependence of true failure strain $\left(\varepsilon_{t}\right.$-fail $)$ for Al-A319 alloys in (a) as-cast; (b) W; and (c) T7 heat treatment conditions. Symbols represent experimental data and the lines are the prediction of the model, respectively.

In addition to yield stress $\left(\sigma_{t-y}\right)$, failure stress $\left(\sigma_{t-\text { fail }}\right)$, and failure-to-strain $\left(\varepsilon_{t-\text { fail }}\right)$ of alloys, in Figure 6, the predictions of other mechanical parameters of interest including the strain hardening exponent $(n)$, strength coefficient $(K)$, and ductility parameter $(A)$ are compared with values calculated based on the Holloman equation $\left(\sigma_{t}=K \varepsilon_{t}^{n}\right)$ with the experimental data. Figure $6 \mathrm{a}$,b shows that there is good agreement between the predicted and experimental values of strength coefficient $(K)$ and ductility parameter $(A)$ with the same some deviations at $210^{\circ} \mathrm{C}$ and $240{ }^{\circ} \mathrm{C}$ for the as-cast condition and the $\mathrm{W}$ condition from $240^{\circ} \mathrm{C}$ to $320^{\circ} \mathrm{C}$. From these figures, it is seen that the strength coefficient $(K)$ increases and the ductility parameter $(A)$ decreases with $\mathrm{W} / \mathrm{T} 7$ heat treatments, respectively, which indicates that the heat treatment will increase the strength coefficient $(K)(\sim 48 \%)$ as well as the true yield stress $\left(\sigma_{t-y}\right)$ and the true failure stress $\left(\sigma_{t-\text { fail }}\right)$ as shown in Figure 4 , and it will decrease the ductility of alloys. Further, it is observed that the general trend of these two parameters (i.e., $K$ and $A$ ) for the $\mathrm{W}$ and T7 samples are similar, although the $K$ and $A$ parameters of $W$ condition are slightly lower and higher, respectively, compared with those from T7 specimen. On the other hand, Figure $6 \mathrm{c}$ shows that there is considerable scatter in the experimental data for the strain hardening exponent $(n)$ and the agreement is relatively poor between the experimental values and the predicted trend, especially at temperatures above $180^{\circ} \mathrm{C}$, which indicates that either the growth or dissolution of precipitates can abruptly affect the mechanical properties.
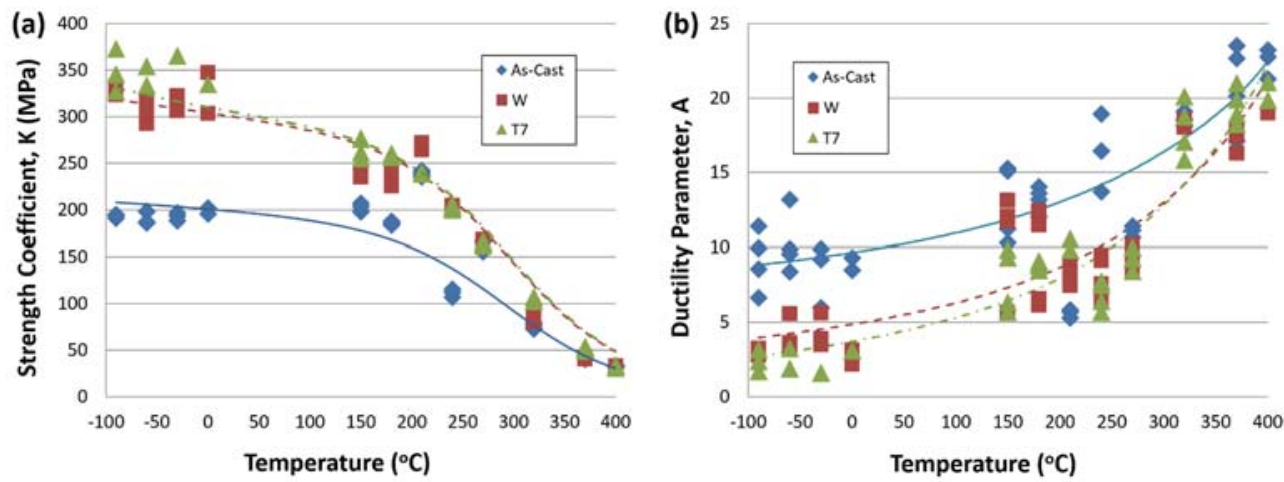

Figure 6. Cont. 


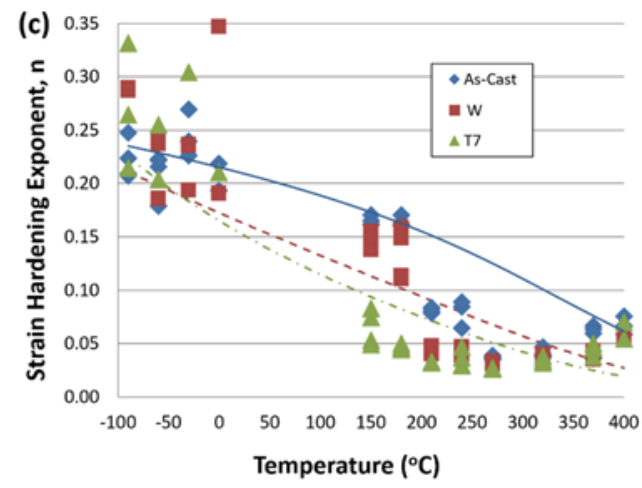

Figure 6. Temperature-dependence of (a) strength coefficient $(K)$; (b) ductility parameter $(A)$; and (c) strain hardening exponent $(n)$, for Al-A319 alloys in various heat treatment conditions. Symbols represent experimental data and the curves are the prediction of the model, respectively.

In Figure 7, the relationships between the ductility parameter $(A)$ and the strain hardening exponent $(n)$ are displayed for the (a) as-cast, (b) W, and (c) T7 specimens. The symbols and curve lines represent the experimental and prediction data, respectively. From the figures, it is clear that, in general, the $A$ and $n$ parameters exhibit an inverse relationship; that is, $A$ decreases and $n$ increases as the temperature decreases. Further, the experimental data in Figure 7 show that there is a complicated temperature-dependent behavior of $n$ and $A$, which can account for the relative inconsistency between experimental and predicted values in Figure $6 c$, and again shows that either the growth or dissolution of precipitates can abruptly affect the mechanical properties. Although there are some deviations from the experimental measurement data, the analytical predictions show reasonable averaged behavior over a wide range of temperatures for as-cast and heat treated specimens.
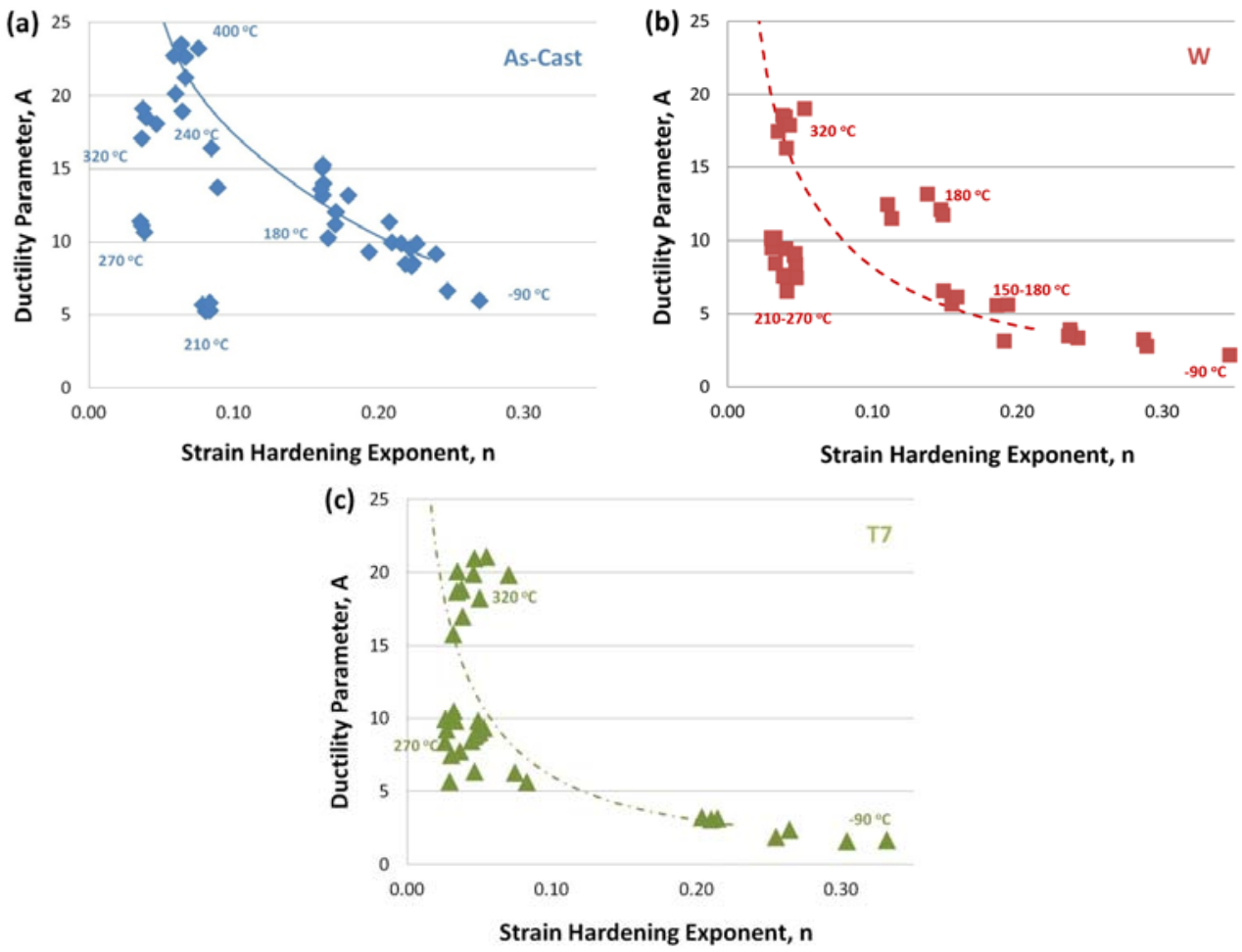

Figure 7. Temperature-dependent relationships of ductility parameter $(A)$ and strain hardening exponent $(n)$ for Al-A319 alloys in (a) as-cast; (b) W; and (c) T7 heat treatment conditions. Symbols represent experimental data, and solid and dashed lines represent predictions of the model, respectively. 
Across Figures 3-7 we have shown that the developed analytical model can predict various mechanical properties such as Young's modulus $(Y)$, true yield stress $\left(\sigma_{t-y}\right)$, true failure stress $\left(\sigma_{t-\text { fail }}\right)$, true failure strain $\left(\varepsilon_{t-\text { fail }}\right)$, strength coefficient $(K)$, ductility parameter $(A)$, and strain hardening exponent $(n)$ of Al-A319 alloys at different temperatures. Although we have only demonstrated that the model can be applied to the Al-A319 material systems at various temperatures with different heat treatment conditions in the current study, it is generally expected that the presented analytical model approach can be applied to predict the mechanical behaviors of precipitation-hardened alloys where the stress-strain curves are described by the Hollomon equation under various temperatures.

\section{Conclusions}

In this work, an analytical model using some empirical parameters was proposed to describe the temperature dependence of Young's modulus $(Y)$, true yield stress $\left(\sigma_{t-y}\right)$, true failure stress $\left(\sigma_{t-\text { fail }}\right)$, and true failure strain $\left(\varepsilon_{t-\text { fail }}\right)$ of precipitation-hardened alloys majorly strengthened by the Orowan strengthening mechanism. Strain hardening exponent $(n)$ and strength coefficient $(K)$ of the Hollomon relation are derivable from these properties, as is the ductility parameter $(A)$. The analytical model is majorly based on the experimentally measured data at a reference temperature (i.e., LT in our work) and three empirical parameters $\left(\Psi, C_{y}=C_{\text {fail }}\right.$, and $\left.Q_{\text {fail }}\right)$. The predictions of the model have been found to provide consistent descriptions with experimental observations for the temperature-dependent tensile mechanical behavior of Al-A319, except in the cases where high temperature results in either dissolution or precipitation of intermetallic phases. In general, it was demonstrated that the model adequately describes the true yield stress $\left(\sigma_{t-y}\right)$, the true failure stress $\left(\sigma_{t-\text { fail }}\right)$, and the true failure strain $\left(\varepsilon_{t-\text { fail }}\right)$ of the Al-A319 material. It is expected that the developed model can be applied to predict the mechanical behaviors of precipitation-hardened alloys strengthened by the Orowan mechanism under various temperatures. Other than the reliability of the prediction of the developed model, the following lists the finding attained through this work.

- The temperature-dependent behavior of Young's modulus $(Y)$ of Al-A319 alloys does not significantly depend on heat treatment conditions of the material. Such temperature-dependent behavior of modulus can be described by adopting the logistic function.

- The loss of stiffness that accompanies with temperature increase can be proportional to the elastic portion of the true yield strain $\left(\varepsilon_{t-y_{L T}}=\sigma_{t-y_{L T}} / Y_{L T}\right)$ at the reference temperature (LT) and the elastic modulus difference $\left(Y_{\mathrm{LT}}-Y\right)$ from the reference temperature (LT). In homogenized materials (i.e., $\mathrm{W}$ and T7 heat treatment conditions in Al-A319), the failure stress $\left(\sigma_{t-\text { fail }}\right)$ is relatively insensitive to heat treatment condition-meaning that for materials of the same grain size, the overall chemical composition of the alloy determines the failure stress.

- The tensile properties of strength coefficient $(K)$ and ductility parameter $(A)$ as calculated from the predicted Young's modulus $(Y)$, true yield stress $\left(\sigma_{t-y}\right)$, true failure stress $\left(\sigma_{t-\text { fail }}\right)$ and true failure strain $\left(\varepsilon_{t-\text { fail }}\right)$ agree with the values estimated from the experimental data.

Acknowledgments: This materials is based upon work supported by the U.S. Army Research laboratory under Cooperative Agreement No. W911NF-15-2-0005. The views, opinions, and conclusions made in this document are those of authors and should not be interpreted the official policies, either expressed or implied, of Army Research Laboratory or the U.S. Government. The U.S. Government is authorized to reproduce and distribute reprints for Government purposes notwithstanding any copyright notation herein.

Author Contributions: J.B. Ferguson developed the model and wrote the manuscript. H.F. Lopez contributed to the experimental testing and K. Cho validated the model and revised the manuscript. C.-S. Kim supervised the progress of the overall work and wrote the manuscript.

Conflicts of Interest: The authors declare no conflicts of interest.

\section{References}

1. Han, Y.Y.; Samuel, A.M.; Doty, H.W.; Valtierra, S.; Samuel, F.H. Optimizing the tensile properties of Al-Si-Cu-Mg 319-type alloys: Role of solution heat treatment. Mater. Design. 2014, 58, 426-438. [CrossRef] 
2. Mohamed, A.M.A.; Samuel, F.H.; Kahtani, S.A. Influence of $\mathrm{Mg}$ and solution heat treatment on the occurrence of incipient melting in Al-Si-Cu-Mg cast alloys. Mater. Sci. Eng. A 2012, 543, 22-34. [CrossRef]

3. Sjolander, E.; Seifeddine, S. The heat treatment of Al-Si-Cu-Mg casting alloys. J. Mater. Process. Tech. 2010, 210, 1249-1259. [CrossRef]

4. Caceres, C.H.; Djurdjevic, M.B.; Stockwell, T.J.; Sokolowski, J.H. The effect of Cu content on the level of microporosity in Al-Si-Cu-Mg casting alloys. Scripta Mater. 1999, 40, 631-637. [CrossRef]

5. Li, Z.; Samuel, A.M.; Samuel, F.H.; Ravindran, C.; Valtierra, S.; Doty, H.W. Parameters controlling the performance of AA319-type alloys: Part I. tensile properties. Mater. Sci. Eng. A 2004, 367, 96-110. [CrossRef]

6. Ferguson, J.B.; Tabandeh-Khorshid, M.; Rohatgi, P.K.; Cho, K.; Kim, C.-S. Predicting tensile and compressive mechanical properties of biomodal nano-aluminum alloys. Scripta Mater. 2014, 72-73, 13-16. [CrossRef]

7. Gerlich, D.; Fisher, E.S. The high temperature elastic moduli of aluminum. J. Phys. Chem. Solids 1969, 30, 1197-1205. [CrossRef]

8. Rincon, E.; Lopez, H.F.; Cisneros, M.M.; Mancha, H. Temperature effects on the tensile properties of cast and heat treated aluminum alloy A319. Mater. Sci. Eng. A 2009, 519, 128-140. [CrossRef]

9. Bouaziz, O. Revised storage and dynamic recovery of dislocation density evolution law: Toward a generalized Kocks-Mecking model of strain-hardening. Adv. Eng. Mater. 2012, 14, 759-761. [CrossRef]

10. Cao, X.; Jahazi, M.; Al-Kazzaz, H.; Medraj, M. Modeling of work-hardening behavior for laser welded magnesium alloy. Int. J. Mater. Res. 2008, 99, 216-221. [CrossRef]

11. Zolotorevsky, N.Y.; Solonin, A.; Churyumov, A.Y.; Zolotorevsky, V. Study of work hardening of quenched and naturally aged Al-Mg and Al-Cu alloys. Mater. Sci. Eng. A 2009, 502, 111-117. [CrossRef]

12. Nes, E.; Marthinsen, K. Modeling the evolution in microstructure and properties during plastic deformation of f.c.c.-metals and alloys-an approach towards a unified model. Mater. Sci. Eng. A 2002, 322, 176-193. [CrossRef]

13. Myhr, O.R.; Grong, O.; Schafer, C. An extended age-hardening model for Al-Mg-Si alloys incorporating the room-temperature storage and cold deformation process stages. Metall. Mater. Trans. A 2015, 46A, 6018-6039. [CrossRef]

14. Rincon, E.; Lopez, H.F.; Cisneros, M.M.; Mancha, H.; Cisneros, M.A. Effect of temperature on the tensile properties of an as-cast aluminum alloy A319. Mater. Sci. Eng. A 2007, 452-453, 682-687. [CrossRef]

15. Dieter, G. Mechanical Metallurgy, 3rd ed.; McGraw-Hill Book Co.: New York, NY, USA, 1986.

16. Talamantes-Silva, M.; Rodríguez, A.; Talamantes-Silva, J.; Valtierra, S.; Colás, R. Effect of solidification rate and heat treating on the microstructure and tensile behavior of an aluminum-copper alloy. Metall. Mater. Trans. B 2008, 39, 911-919. [CrossRef]

(C) 2016 by the authors; licensee MDPI, Basel, Switzerland. This article is an open access article distributed under the terms and conditions of the Creative Commons by Attribution (CC-BY) license (http://creativecommons.org/licenses/by/4.0/). 